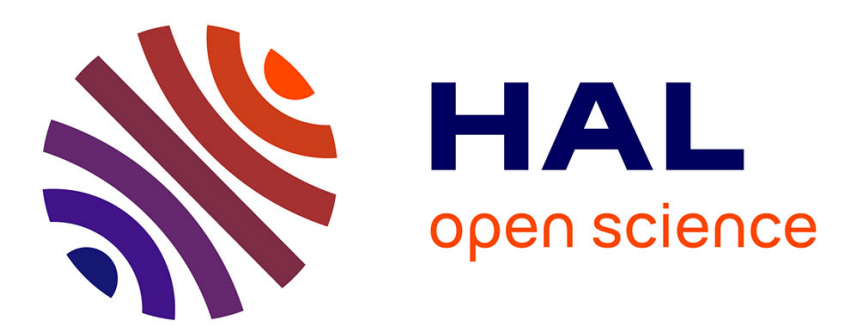

\title{
Bottom-Up or Top-Down? Campbell's Rationalist Account of Monothematic Delusions
}

Tim Bayne, Elisabeth Pacherie

\section{To cite this version:}

Tim Bayne, Elisabeth Pacherie. Bottom-Up or Top-Down? Campbell's Rationalist Account of Monothematic Delusions. Philosophy, Psychiatry and Psychology, 2004, 11 (1), pp.1-11. ijn_00000346v2

\author{
HAL Id: ijn_00000346 \\ https://hal.science/ijn_00000346v2
}

Submitted on 12 Mar 2005

HAL is a multi-disciplinary open access archive for the deposit and dissemination of scientific research documents, whether they are published or not. The documents may come from teaching and research institutions in France or abroad, or from public or private research centers.
L'archive ouverte pluridisciplinaire HAL, est destinée au dépôt et à la diffusion de documents scientifiques de niveau recherche, publiés ou non, émanant des établissements d'enseignement et de recherche français ou étrangers, des laboratoires publics ou privés. 


\section{BOTTOM-UP OR TOP- Down? CAMPBELl's Rationalist AcCOUnT of Monothematic DELUSIONS}

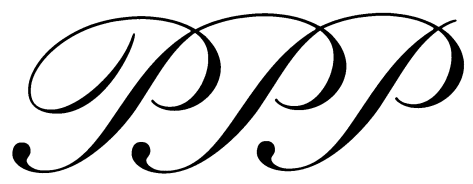

ABSTRACT: A popular approach to monothematic delusions in the recent literature has been to argue that monothematic delusions involve broadly rational responses to highly unusual experiences. Campbell (2001) calls this the empiricist approach to monothematic delusions, and argues that it cannot account for the links between meaning and rationality. In place of empiricism, Campbell offers a rationalist account of monothematic delusions, according to which delusional beliefs are understood as Wittgensteinian framework propositions. We argue that neither Campbell's attack on empiricism nor his rationalist alternative to empiricism is successful.

KEYWORDS: monothematic delusions, rationality, meaning, rationalism, empiricism

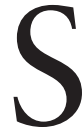
OME OTHERWISE RATIONAL PEOPLE appear to believe strange things. Sometimes people believe that someone, usually a near relative or member of their family-often their spouse- has been replaced by an impostor. Sometimes people believe that they are dead. These two delusions-known as the Capgras and Cotard delusions, respectively-are instances of monothematic delusions, because they are limited to very specific topics. Other monothematic

\section{TIM BAYNE AND Elisabeth PACHERIE}

delusions involve the delusion that one is being followed by known people in disguise (the Frégoli delusion) or that the person one sees in the mirror is someone else (mirrored-self misidentification). We focus on the Capgras delusion in our discussion.

Delusions raise many issues of interest for philosophical psychology. Central among these issues is the question of what kind of mental states they are. One view-endorsed by Jaspers (1963) and more recently by Berrios (1991) and Sass (1994)—holds that, despite appearances to the contrary, delusions are not contentful states. This view is sometimes called the expressivist (Gerrans 2001) or non-assertoric (Young 1999) account. On a second account of delusions, developed recently by Currie and collaborators (Currie 2000; Currie and Jureidini 2001; Currie and Ravenscroft 2002), delusions are cognitive hallucinations: they are imaginative states that are misidentified by their subjects as beliefs. It's not clear whether Currie and co-authors wish to extend their account to monothematic delusions, but it certainly could be so extended. ${ }^{1}$

Although the expressivist and "cognitive hallucination" accounts of delusions are important, 
we set them aside here. Instead, we focus on a dispute between two doxastic accounts of monothematic delusions-that is, accounts that hold delusions to be beliefs of a certain kind. The first account holds that monothematic delusions are beliefs that are broadly rational responses to highly unusual experiences. Following Campbell (2001), we will call this the empiricist approach to monothematic delusions. Some versions of empiricism hold that the only deficit the patient suffers from is an unusual experience, and that the delusional belief is a completely rational response to the patient's experience (Maher 1999). More common in the recent literature are twofactor versions of empiricism, in which monothematic delusions involve an unusual experience plus a reasoning bias or deficit of some kind (Davies and Coltheart 2000; Davies et al. 2001; Ellis and Young 1990; Stone and Young 1997; Young 2000). Both versions of empiricism are united in regarding the delusional patient as broadly rational.

The second model we examine is that offered by John Campbell (2001). Campbell argues that empiricist accounts of monothematic delusions face serious objections, and in their place offers what he calls a rationalist account, according to which delusions are understood as Wittgensteinian framework propositions: the Capgras patient's assertion that his wife has been replaced by an impostor expresses a belief, but the belief that it expresses does not have the same content as the belief that I would express were I to assert that the patient's wife had been replaced by an impostor. In this paper, we argue that neither Campbell's attack on empiricism nor his rationalist alternative to empiricism is successful.

\section{Problems With EMPIRICISM}

Empiricist accounts of monothematic delusions are committed to the following three claims:

(1) Bottom-up etiology thesis: The proximal cause of the delusional belief is a certain highly unusual experience.

(2) Rationality thesis: The delusional belief is a broadly rational response to the patient's unusual experience.
(3) Preservation of meaning thesis: The terms the deluded subject uses to express the delusional beliefs retain their usual meaning.

There are various ways in which one might relate these three components, but one plausible story is this. (We tell this story as it applies to the Capgras delusion, but one could attempt to tell similar stories for other monothematic delusions.) One begins with Ellis and Young's two-component model of face recognition, initially developed to account for prosopagnosia (Ellis and Young 1990). On this model, face recognition involves two information-processing pathways: a visuo-semantic pathway that constructs a visual image that encodes semantic information about facial features, and a visuo-affective pathway that produces a specific affective response to familiar faces (the feeling of familiarity). In prosopagnosia, the visuo-semantic pathway is damaged, which accounts for the patient's inability to recognize faces, whereas the visuoaffective pathway remains intact, which explains why they retain covert recognition of familiar faces. ${ }^{2}$ Ellis and Young proposed that Capgras might be a mirror image of prosopagnosia, with the affective pathway damaged but the visuosemantic pathway intact. The belief that a close relative has been replaced by an impostor would be a response to their unusual experiences of their spouse's face: one's spouse is recognized as looking like one's spouse, but the normal feeling of familiarity is absent (and, indeed, a feeling of unfamiliarity is present). So, (1) has some support. $^{3}$

Second, one might think that (1) supports (2). There are two ways in which the connection between (1) and (2) might be developed (see Davies et al. 2001). On the one hand, it might be that the patient's experience has content that directly warrants the delusional belief. On this model, the content of the Capgras patient's visual perception of their spouse is roughly, "The woman I am looking at is not my wife." The transition from this experience to the patient's delusional belief is akin to the transition from a visual experience that, say, there is a dog in front of one, to the belief that there is a dog in front of one: there might not be a perfect match between 
the content of the perceptual state and that of the doxastic state-perhaps the former has nonconceptual content and the latter conceptual content-but there will be a fairly intimate relationship between the two. We call this the endorsement model, on the grounds that adopting the delusional belief involves doxastically endorsing the content of the delusional perception. On the other hand, it might be that the content of the Capgras patient's experience is less rich, and may not be about their spouse at all; perhaps it involves nothing more than a strange feeling, which happens to be correlated with looking at one's spouse. On this model, the patient adopts the delusional belief in an attempt to explain why he has this unusual experience whenever he looks at his spouse. At some level he thinks to himself, "The reason why I have this strange experience whenever I look at this person is because she is an impostor." On this explanationist version of the two-factor model, there is less pressure to think of the patient's perceptual experience as encoding the content of the Capgras delusion.

Finally, (2) may be thought to support (3). Insofar as the delusional belief is supported by the person's experiences-either directly or by way of abductive (explanatory) inference-it is possible to preserve a literal interpretation of his words. Indeed, Stone and Young take this to be an important advantage of the empiricist account, claiming that "It has been the burden of our explanation of the Capgras delusion to see it as an understandable (i.e. sense-making) interpretation of a perceptual deficit" $(1997,357)$. Proponents of two-factor versions of empiricism agree that delusional patients are not completely or fully rational-they recognize that deluded patients are not always responsive to tensions between their delusional belief and their other beliefs in the ways in which a rational person should be-but they deny that these departures from the norms of rationality are serious enough to undermine the preservation of meaning thesis.

On our reading of his position, Campbell rejects (1), (2), and (3). On his view, monothematic delusions are neither caused nor justified by unusual experiences, and the terms in which the patient expresses his belief do not retain their usual meaning. Campbell motivates his position by arguing that the empiricist model that we've just outlined fails. So, the first order of business is to examine Campbell's criticisms of empiricism. In the second half of this paper we turn the critical spotlight on Campbell's own account. We begin with (1): the bottom-up etiology thesis.

Campbell's first worry here is that the mere lack of affect in the perception of a woman does not itself constitute the perception's having a particular content, let alone the content "that [perceived] woman is not that [remembered] woman" $(2001,96)$. According to Campbell, it is doubtful whether an experience could have this content without top-down loading by the patient, where by top-down loading he seems to mean that the perceptual state inherits its content from belief. But if we need to appeal to topdown loading then the empiricist game is over, because the empiricist could not appeal to the content of the patient's perceptual or affective states to explain why they form the delusional belief.

Let us start with the claim that the mere lack of affect in the perception of the patient's wife could not itself constitute the perception's having a particular content. We think that this is right: one should not confuse the lack of experience with the experience of a lack. But we also think that the lack of affect can very easily generate the experience of a lack of affect. Here it may be useful to draw a parallel with the experience of patients with cerebral achromatopsia, the loss of color vision as a result of damage to the extrastriate cortex. Cerebral achromatopsia is interesting in at least three respects. First, persons who develop cerebral achromatopsia report that they see a monochromatic world, all in shades of gray. It would be wrong (or at least misleading) to say that their visual experience differs from the visual experience of subjects with normal color vision only in that it lacks the experience of color. Rather, the visual experience of these patients has the content that color shades have been replaced by shades of gray. Second, these subjects are perfectly aware that their visual experience of the world is different from what it 
was before the onset of their condition. Third, given that these subjects are also very often unable to imagine or remember colors (Farah 1988), their awareness of their deficit is not based on a comparison of their present experience with consciously recollected experiences of colors. Rather it seems to be based on meta-memory. ${ }^{4}$ Similarly, we suggest, Capgras patients do not merely fail to experience the affect of familiarity when seeing their loved ones; rather, the normal feeling of familiarity has been replaced by a disturbing feeling of unfamiliarity and estrangement.

There is, however, an important difference between the Capgras delusion and achromatopsia: whereas the patient with achromatopsia is aware of the particular perceptual attributes that she has lost, the Capgras patient is unable to articulate precisely what it is that is different about his experience. Nevertheless, Capgras patients seem to realize that something has changed in the nature of their experiences, because they often refer to the content of their experiences to justify their delusional beliefs. One Capgras patient remarked, "there's someone like my son's double which isn't my son. I can tell my son because my son's different but you have to be quick to notice it" (Young et al. 1993, 696; see also Merrin and Silberfarb 1976). The same point is true of patients with the Cotard delusion: "What the [Cotard] patients often give as evidence of their non-existence or death is that they don't have proper feelings" (Young and Leafhead 1996, 149).

Campbell could concede this point and yet maintain that an experience could have the content "I have a strange feeling of unfamiliarity now" without having the content "This [perceived] woman is not that [remembered] woman." Moreover, he might claim that a visual experience could not have that content without top-down loading. At this point, Campbell might refer us to the patient who looked at a row of empty marble tables and had the delusion that the world was about to end. As he points out, it is difficult to see how a person could have the experience with the content that the world was about to end without top-down loading (2001, 96). Similarly, one might argue that one could not have an experience with the content that a perceived person is not a remembered person without top-down loading, because the concepts involved in this experience are not sensory.

There are two issues to consider here. The first is whether the two-factor theorist needs to accept Campbell's characterization of the deluded patient's perceptual state. The second issue is whether Campbell is right to think that a perceptual state could not acquire that content without topdown loading. We tackle these questions in turn.

A proponent of what we called the explanationist version of the two-factor model need not accept that the patient's perception has the content "This [perceived] woman is not that [remembered] woman." Such models think of the content of the patient's perception as being much poorer, something like, "this person looks a bit strange." On this view, the two-factor theorist does not need to explain how the patient's visual experience could have nonsensory content, because according to her it does not. This is not to say that the explanationist line is unproblematic-one might well put pressure on the rationality of the patient's abductive inference-but it does not face this problem. (The explanationist has a hard job explaining why the patient makes the particular abductive inference she does, but she has less difficulty giving an account of the content of the patient's perceptual state. The proponent of the endorsement account has precisely the opposite problem: her problem is explaining how the patient's perceptual experience could acquire the content of the Capgras delusion.)

The fact that the explanationist can block Campbell's first objection is of little comfort to us, because we are not much tempted by the explanationist version of the two-factor account. Instead, we prefer the endorsement version of the two-factor approach, according to which the patient's visual perception has the content "This [perceived] woman is not the person who I think of as my wife," or something very close to this. So we need to explain how a perceptual state could have this content without inheriting it from the belief that the person one is looking at is not the person one remembers as one's wife. 
The central issue here is how the Capgras patient thinks of his spouse. One possibility would be that he thinks of his wife as "whoever it is that produces that affective response in me." Campbell rejects this proposal on the grounds that "that it is not, actually, how we ordinarily think of our spouses. We do, in fact, tend to think in terms of our memories of them" $(2001,92)$. It is clear, moreover, that what he has in mind are propositionally articulable episodic memories of past episodes in one's common life. We think that Campbell may be overemphasizing the importance of propositionally articulable episodic memories here and underestimating the role of affective memory. The delusions of Capgras patients primarily concern close relatives, loved ones. We may well spend more time in the course of our life with colleagues than with our family and share with those colleagues as many episodic memories as we do with our relatives. Colleagues may be as familiar as relatives in this sense. Yet, however much we like our colleagues, our affective ties to close relatives are normally much stronger. It may be true that the way we think of other people generally is not in terms of the affective response they produce in us, but affect seems to play an essential role in the way we think of our relatives. One normally thinks of one's spouse as this person one loves (or hates in unhappy relationships). When we think of them in terms of the memories we have of them, the episodic memories that come to mind tend to be memories of emotionally significant episodes, namely, episodes where your emotional response to your spouse or hers to you played an important role, and episodes where your shared emotional responses to some third object reinforced your emotional ties to one another. Episodic memories may be important to how we think of our spouse not so much in themselves but insofar as they function as cues for the recall of affective memories. Campbell's suspicion that the experience of the Capgras patients could not have the content "This [perceived] woman is not that [remembered] woman" may be unfounded if, as we propose, memories of relatives are typically deeply affect-laden.

Perhaps Campbell's worry is that reference to particular individuals cannot enter into percep- tual content. This worry-which might not be Campbell's-also seems to be unfounded. Suppose that you know two identical twins: Jules and Jim. You can tell Jules and Jim apart just by looking at them, but you have no idea how you do this. The algorithm that one's face-processing system uses to discriminate Jules from Jim is not available to introspection. Still, it is clear that you can do this. Looking at Jules you say to yourself, "That is Jules," and this judgment is warranted by the fact that it is part of the content of one's perceptual state that the object of one's current perception is Jules (and not just someone who is qualitatively indiscernible from Jules).

We turn now to what we take to be Campbell's second and third objections to empiricism. Campbell holds that the empiricist account fails to appreciate the strength of the link between rationality and meaning. Following Quine's lead, Campbell argues that there is a constitutive link between one's knowledge of the meaning of a term or concept and one's use of the term or concept in reasoning. More precisely, his claim is that the use one makes of a term or concept in reasoning must be systematically causally dependent on the meaning we associate with it. Given this constitutive link, if the use one makes of a term in reasoning is sufficiently unlike the canonical use of this term, it becomes questionable whether one really grasps its meaning.

Campbell claims that even if the patient has an experience with the content "This [perceived] woman is not that [remembered] woman," forming the belief that this perceived woman is not that remembered woman is not rational. The patient should also take his other beliefs (and experiences) into account when moving from the experience to the belief; in short, he should verify the judgment.

How would you go about verifying such a judgment? You would have to check that the woman you currently perceive is indeed the one of whom you have all those memories. The canonical way to do this would be to find out whether you have shared memories of the events in which you both took part. And the canonical way to do that would be to discuss those past events. It is not that your memories have to coincide at all points or even that they have to be correct memories, but that they recognizably derive from the same episodes. Since the patient does not use 
this way of checking who it is that is before him, he seems to have lost his grip on the meaning of the word (Campbell 2001, 90-91).

Because the delusional patient seems to have lost his grip on the meaning of the words he uses, we lack any precise way of characterizing the content of his delusion. He says, "My wife has been replaced by an impostor," but we are prevented from ascribing the corresponding belief to him.

Campbell has raised an important challenge for empiricist accounts, and there is much that needs to be said here. In what follows, we sketch some of the reasons for finding Campbell's argument problematic.

First, if, as we propose, memories of relatives are typically deeply affect-laden, then one canonical way of verifying that the person you currently perceive is not your wife would be to check whether the feeling of unfamiliarity persists over time and accompanies all your episodes of seeing that person. Thus, the recurring character of the experience of unfamiliarity-which we assume characterizes the Capgras syndrome-may be taken as evidence that the judgment is correct.

Second, Campbell conflates-or at least fails to clearly distinguish - two reasons why Capgras patients might fail to engage in canonical ways of verifying their judgments. One possibility is that they lack the required inferential competence: they have no idea what the canonical procedures of verification in question are. This seems to be the position that Campbell takes. A second possibility is that, although they have the requisite competence, they are unwilling to employ it. There may be two reasons for this unwillingness. The first has to do with questions of context: canonical procedures of verification are only canonical relative to normal, or canonical, contexts, where they are likely to succeed. One may not be inclined to engage in canonical procedures if one thinks the context is not canonical. Capgras patients tend to be of a suspicious cast of mind and often have paranoid or persecutory tendencies. This may explain not only why they assign a high initial probability to the hypothesis that their spouse has been replaced by an impostor, but also why they do not use canonical verification procedures to check it. If you are strong- ly inclined to believe that the person you are talking to is an impostor, you might think that there is little point in talking to them, for they are unlikely to be cooperative and are probably intent on deceiving you. Furthermore, if you think that the impostor is a full doppelganger of your wife, then you might think that checking her memories would be pointless, for a full doppelganger of your wife will share her memories. In short, it is not at all clear that the Capgras patient would consider that the verification procedures that Campbell demands are appropriate to the context at hand.

The second reason why Capgras patients might be unwilling to engage in such verification procedures has to do with motivation. On an empiricist account, a motivational deficit would not be surprising given that the root of the patients' impairment is affective. Their problem would then be one of inferential motivation rather than inferential competence.

Third, Campbell's canonical verification procedures have to do with theoretical reasoning, but theoretical reasoning is only one possible manifestation of one's grasp of the meaning of terms. Engaging in practical reasoning seems equally important. And although patients with monothematic delusions display an often surprising lack of delusional-generated activity, it would not be correct to say that Capgras patients do not engage in any such behavior. Capgras patients do act on the basis of their beliefs, sometimes violently (de Pauw and Szulecka 1988). A recent view of 260 Capgras cases found violence in $18 \%$ (Förstl et al. 1991). One such patient accused his stepfather of being a robot and decapitated him to look for the batteries in his head (Blount 1986). Other Capgras patients have lodged complaints with the police for the abduction of their spouse. As Young (1999) notes, this is a pretty good indication that their claims should be taken literally. And in their analysis of Cotard's original case reports, Young and Leafhead (1996) note that all of Cotard's patients showed some form of delusion-related behavior (e.g., refusing to eat, move, or defecate).

Finally, at least some Capgras patients seem to be aware of how implausible their claims may 
sound to others. Consider the following wellknown exchange:

E: Isn't that [two families] unusual?

S: It was unbelievable.

E: How do you account for it?

S: I don't know. I have tried to understand it myself and it was virtually impossible.

S: What if I told you I don't believe it?

E: That's perfectly understandable. In fact, when I tell the story, I feel that I'm concocting a story . . . it's not quite right, something is wrong.

E: If someone told you the story what would you think?

S: I would find it extremely hard to believe. I should be defending myself. (Alexander, Stuss, and Benson 1979, 335)

It is difficult to see how the Capgras patient might grasp the fact that others find it difficult to believe their story if they have lost their grip on the meaning of the terms they use.

Although we admit that delusional patients are less than fully rational-and that these failures of rationality present a challenge for empiricists' accounts-we remain unconvinced that these failures are drastic enough to warrant the claim that the delusional patients have lost their grip on the meaning of the terms in which they frame their delusion.

\section{Campbell's Solution: Delusional Beliefs as Framework Propositions}

We turn now to Campbell's rationalist alternative to empiricism. There are two central questions here: (1) what exactly does the rationalist account involve? and (2) does it provide a better explanation or characterization of monothematic delusions than empiricism?

Campbell's account involves two components that we think it useful to distinguish and treat separately. The first component is etiological: monothematic delusions involve a "top-down disturbance in some fundamental beliefs of the subject, which may consequently affect experiences and actions" $(2001,89)$. The second component is the idea that delusions can be usefully regarded as Wittgensteinian framework propositions. Campbell suggests that "My spouse has been replaced by an impostor" has, for the Capgras patient, the kind of status that, according to Wittgenstein, "There are a lot of objects in the world," "the world has existed for quite a long time," and "there are some chairs and tables in this room" have for most of us. What exactly that status amounts to is somewhat unclear, but it seems to involve the idea of immunity to ordinary empirical scrutiny. As far as we can see, the two components of Campbell's account are logically independent. On the one hand, a belief can function as a framework proposition without being top-down: presumably "there are some chairs and tables in this room" is such a belief. And on the other hand, a belief can be top-down without being framework. A belief could arise as a direct result of organic malfunction without being immune to ordinary empirical scrutiny. We will examine the claim that delusions are framework propositions in the second half of this section; for now we focus on the etiological component of Campbell's position.

There are a number of things that one might mean by describing delusional beliefs as topdown. What Campbell means is that delusional beliefs are neither caused nor justified by unusual experiences. ${ }^{5}$ But Campbell does not think that delusional beliefs are inferred from other beliefs. Instead, he suggests that they arise as a direct result of organic malfunction $(2001,97){ }^{6}$

Campbell notes that there seems to be a sense in which it is easier to explain a change in experience as a direct result of organic malfunction than it is to explain a change in belief as a direct result of organic malfunction (see also Davies and Coltheart 2000,8). The reasons for this sense of unease are not clear; it might, perhaps, have something to do with the holism of belief as opposed to the (relative) encapsulation of perception, and it might have something to do with the notion that we have more control over the formation of beliefs that we do over the formation of perceptual states. But whatever its cause, its not clear that it is justified. It is widely granted that there are emotional routes to belief: beliefs can be generated and maintained by the emotional functions they serve. And it certainly seems conceivable that certain beliefs (and not 
just concepts) might be innate. Indeed, some theists have claimed precisely this, and similar ideas have been suggested in cognitive science regarding various folk domains, such as folk physics and folk biology. If these nonevidential routes to belief are possible, there seems little reason to rule out the rationalist conception of belief formation a priori.

But given his earlier objections to empiricism it is rather puzzling to find Campbell endorsing the rationalist account of belief formation. Campbell claims that the empiricist fails to secure the rationality of belief acquisition in the Capgras patient, because the content of their experience does not justify the belief. But on Campbell's own account the Capgras patient does not have any reasons-not even poor reasons-for his delusional belief! One might think that acquiring and maintaining a belief without any reasons is more irrational than acquiring and maintaining it for poor reasons. ${ }^{7}$

A further problem for Campbell is that of explaining why monothematic delusions cluster around particular topics. If delusions arise directly from brain damage why do we not find as many delusional topics as there are possible beliefs? Why, for example, do we not find delusional patients who believe that, say, their fridge magnets have been replaced by impostors, or that dogs like Opera, or whatever. Of course, monothematic delusions do not have quite the monothematicity that they are often presented as having - there are cases of delusional misidentification for nonhuman animals (Ramachandran and Blakeslee 1998) and inanimate objects (Abed and Fewtrell 1990; Anderson 1988; Castillo and Berman 1994; Christodoulou 1977; Green 1989; Rastogi 1990)—but such cases are noticeably less common than delusions of misidentification for close family members. Furthermore, even these nonstandard misidentification delusions fall into a certain category: they involve familiar and emotionally significant animals and objects (although, see Ball and Exworthy 1990). On the rationalist account of delusion formation, it is quite unclear why there should be any clustering in the contents of monothematic delusions.

We are also puzzled by the question of how a top-down account of delusions could explain the damage to the autonomic system that one finds in the Capgras and Cotard delusions. Is this caused by the delusional belief? That seems unlikely. ${ }^{8}$

We turn now to the claim that delusional beliefs are framework propositions. Unfortunately, Campbell is none too clear about what exactly a framework proposition is, but the notion seems to have both epistemic and semantic content. Framework propositions have a privileged epistemic status: "they are not themselves, in any ordinary way, subject to empirical scrutiny" (2001, 96f). Second, the notion of a framework belief has semantic implications: "Wittgenstein's notion of a framework proposition was never worked out in great detail. But it is certainly part of the picture here that a change in framework principles would bring with it a change in the meanings of the terms used" $(2001,98)$. Campbell seems to think these epistemic and semantic points are closely related. We are skeptical of this claim - surely the belief that God exists could be framework for one person without being framework for another-but we will grant it here. The issues on which we wish to focus are whether delusions really are immune to ordinary empirical scrutiny, and whether the meaning of the patient's words has changed.

Are monothematic delusions "immune to ordinary empirical scrutiny?" They are certainly very resistant to counterevidence, and in this respect they function as framework propositions. One of the very puzzling features of delusions is that patients often revise their background beliefs rather than their delusions when forced to confront inconsistencies between the two. Consider the following report of a conversation between JK, a Cotard patient, and Young and Leafhead.

We asked her during the period in which she claimed to be dead whether she could feel her heart beat, whether she could feel hot or cold and whether she could feel whether her bladder was full. JK said that since she had such feelings even though she was dead they clearly did not represent evidence that she was alive. (Young and Leafhead 1996, 158).

$\mathrm{JK}$ is obviously not indifferent to the tension between her delusional state and her background 
beliefs (which, incidentally, suggests that she has not lost her grip on the meanings of the words she uses), but rather than retain her background beliefs concerning the marks of being alive, she retains the delusion that she is dead. So in this respect her delusion functions as a framework belief.

But the story is not quite so simple, because deluded patients often appreciate the implausibility of their beliefs. "If you ask 'What would you think if I told you that my wife has been replaced by an impostor?,' you will often get answers to the effect that it would be unbelievable, absurd, an indication that you had gone mad" (Young 1998, 37). If the Capgras patient really does regard his delusional beliefs as framework, then why is he puzzled by the thought that other people might share his belief? After all, do we not assume that what is framework for us will normally also be framework for other people? Of course, there are situations in which we do not make this assumption: the person who has undergone a religious conversion need not have forgotten about his earlier outlook on the world and may have no difficulty understanding that other people do not share his views. But if you asked such a person what they would think if you also believed what they believed, you would not expect to be told that it would be "unbelievable, absurd, an indication that you had gone mad.”

A second objection to the framework proposal is that the delusions are often quite encapsulated. One would expect framework beliefs to play a pivotal role in structuring the patient's thought and action. The ability of a delusional belief to function as a framework proposition is dependent, one might think, on it being integrated into the patient's practical and theoretical behavior. But although delusional patients sometimes act on their beliefs, this belief-related behavior is far from systematic.

We turn, finally, to the semantic component of Campbell's position. Campbell's idea here, we take it, is that understanding delusional beliefs as framework propositions is the only way to preserve the constitutive links between meaning and rationality. (Note that it need not be any part of
Campbell's position that the delusional patient is fully rational; after all, there seems to be something paradigmatically irrational in taking the content of the delusional belief as a framework proposition.) Capgras patients fail to engage in the canonical behavior that is bound up with the belief that one's spouse has been replaced by an impostor because this is not what they believe.

Campbell says that "The really key question about the deluded subject is how the use that she makes of the terms in which she frames her delusion relates to her knowledge of the meanings of the terms" $(2001,95)$. Fair enough. But what is Campbell's answer to this question? Has the patient completely lost her grip on the meanings of the terms involved (wife, this woman, etc.), or has she lost her grip on them only in the context of framing her delusion? We are not sure what Campbell's position is here, but we think he adopts the latter position. That would seem to be the better position for a rationalist to take. The Capgras patient seems to know what wife, this woman, and so on mean. He might be happy to identify his wife as his wife when talking to her on the telephone, and in such contexts his use of the relevant terms would seem to be perfectly standard. But why should the patient lose his grip on the meanings of the words only in the context of delusional utterances? Is it really plausible that one's grip on the meaning of a term could be context sensitive in this manner? We find that hard to believe. Indeed, we find it hard to believe that Campbell believes it, as it seems to run counter the meaning holism that he invokes in support of the view that delusions are framework beliefs.

What does the Capgras patients believe if not that his wife has been replaced by an impostor? What does the patient mean by "This woman is not my wife," if not that the woman he is looking at is not the same person as the woman he has memories of being married to? It is not at all clear that a better interpretation of the patient's utterance is available. Note the contrast between this case and the case that Campbell uses to motivate the claim that there is a constitutive link between rationality and meaning. Campbell presents a case in which a confused tourist says 
to you "The Statue of Liberty has a rather crowded location in the middle of Trafalgar square in London, but anyone would have to admire the lions at its base; such a statue could only be English." As he rightly says, everything falls into place when one realizes that the person means to be referring to Nelson's column by "the Statue of Liberty." But the rhetorical force of this example is misplaced, for it does not transfer to the Capgras patient. As far as we can see, there is no other translation of what the Capgras patient says according to which everything falls into place. Describing the Capgras patient's belief as a framework proposition fails to advance our understanding of what he believes or why he believes it.

Wittgenstein once said that if lions could talk we would not understand them. Campbell's view seems to be that although delusional patients can talk, we cannot understand them. What is curious is that they seem to be able to understand us.

\section{ACKNOWLEDGMENTS}

A preliminary version of this paper was delivered to a Macquarie University philosophy seminar, and we are grateful to the audience for their comments. We are also grateful to the Macquarie University Delusions Group (Max Coltheart, Anne Aimola Davies, Martin Davies, Melissa Green, Robyn Langdon, and Ryan McKay) for discussions on these issues, and to George Graham and Jakob Hohwy for their comments on a previous draft. This research was supported by the Macquarie University Research Grants Scheme, and we are very grateful for its support.

\section{Notes}

1. See Bayne and Pacherie (forthcoming) for a critical discussion of Currie's account of delusions.

2. Note that prosopagnosia is not quite the mirror image of Capgras syndrome, for prosopagnosics have lost the conscious (overt) feeling of familiarity towards familiar faces.

3. Note that on this account one might expect patients with the Capgras delusion to also suffer from the delusion of subjective doubles (the belief that duplicates of you exist), or at least mirrored self-misidentification (mistaking one's image in the mirror for another person), for presumably the Capgras patient would not have the normal experience of familiarity on looking at his own face in the mirror. In fact, Capgras delusion and the delusion of subjective doubles are frequently associated (Weinstein, 1996); indeed, one of Capgras' original patients also experienced the delusion of subjective doubles.

4. A typical instance of meta-memory would be your knowing that you know the name of a certain person and knowing her name is not, say, Jones, while at the same time being unable to retrieve it.

5. One could also hold a top-down account on which the experience is importantly influenced by attitudes and attributional styles, rather than beliefs as such. See, for example, Garety, 1991; Garety and Freeman, 2000; Kaney and Bentall, 1989).

6. Note that Campbell need not-and probably should not-be read as thinking of the relationship between the brain damage and the belief as causal. The particular way in which a rationalist conceives of this relation will depend on their metaphysics of mental states; one could think of this relationship in terms of supervenience rather than causation.

7. This claim raises a number of tricky issues. For example, it supposes that we have an account of what it is to have a reason for a belief. There is much that could be said, but we lack the space to pursue these issues here.

8. We thank Max Coltheart for this point.

\section{REFERENCES}

Abed, R. T., and W. D. Fewtrell. 1990. Delusional misidentification of familiar inanimate objects. British Journal of Psychiatry 157:915-917.

Alexander, M. P., D. T. Stuss, and D. F. Benson. 1979. Capgras' syndrome: A reduplicative phenomenon. Neurology 29:334-339.

Anderson, D. N. 1988. The delusion of inanimate doubles. British Journal of Psychiatry 153:694699.

Ball, C., and T. Exworthy. 1990. Capgras' syndrome and town duplication. British Journal of Psychiatry 154:889-890.

Bayne, T., and E. Pacherie (forthcoming). In defenxe of the doxastic conception of delusions. Mind and Language.

Berrios, G. 1991. Delusions as "wrong beliefs": A conceptual history. British Journal of Psychiatry 159:6-13.

Blount, G. 1986. Dangerousness of patients with Capgras syndrome. Nebraska Medical Journal 71:207.

Campbell, J. 2001. Rationality, meaning and the analysis of delusion. Philosophy, Psychiatry, and Psychology 8, no 2/3:89-100. 
Castillo, P. M., and C. W. Berman. 1994. Delusional gross replacement of inanimate objects. British Journal of Psychiatry 164:693-696.

Christodoulou, G. N. 1977. The syndrome of Capgras. British Journal of Psychiatry 130:556-564.

Currie, G. 2000. Imagination, delusion and hallucinations, in Pathologies of Belief (pp. 167-182). ed. M. Coltheart, and M. Davies. Oxford: Blackwell Publishers.

Currie, G., and J. Jureidini. 2001. Delusion, rationality, empathy. Philosophy, Psychiatry, \& Psychology 8, no. 2/3:159-162.

Currie, G., and I. Ravenscroft. 2002. Recreative Minds. Oxford: Oxford University Press.

Davies, M., and M. Coltheart. 2000. Introduction. Mind and Language 15:1-46.

Davies, M., M. Cotheart, R. Langdon, and N. Breen. 2001. Monothematic delusions: Towards a twofactor account. Philosophy, Psychiatry, \& Psychology 8, no. 2/3:133-158.

de Pauw, K.W., and T. K. Szulecka. 1988. Dangerous delusions: Violence and the misidentification syndromes. British Journal of Psychiatry 152:91-97.

Ellis, H. D., and A. W. Young. 1990. Accounting for delusional misidentifications. British Journal of Psychiatry 157:239-248.

Farah, M. 1988. Is visual imagery really visual? Overlooked evidence from neuropsychology. Psychological Review 95, no. 3:307-317.

Förstl, H., O. P. Almeida, A. M. Owen, A. Burns, and R. Howard. 1991. Psychiatric, neurological and medical aspects of misidentification syndromes: A review of 260 cases. Psychological Medicine 21:905-910.

Garety, P. 1991. Reasoning and delusions. British Journal of Psychiatry 159:14-18.

Garety, P. A., and D. Freeman, D. 2000. Cognitive approaches to delusions: A critical review of theories and evidence. British Journal of Clinical Psychology 38:113-154.

Gerrans, P. 2001. Delusions and performance failures. Cognitive Neuropsychiatry 6, no. 3:161-173.

Green, B. H. 1989. Capgras' syndrome. British Journal of Psychiatry 154:270-271.
Jaspers, K. 1963. General Psychopathology. Trans. J. Hoenig, and M.W. Hamilton. Manchester, UK: Manchester University Press.

Kaney, S., and R. P. Bentall. 1989. Persecutory delusions and attributional style. British Journal of Medical Psychology 62:191-198.

Maher, B. 1999. Anomalous experience in everyday life: Its significance for psychopathology. The Monist 82:547-570.

Merrin, E. L., and P. M. Silberfarb. 1976. The Capgras phenomenon. Archives of General Psychiatry 33:965-968.

Ramachandran, V. S., S. and Blakeslee. 1998. Phantoms in the Brain. London: Fourth Estate.

Rastogi, S. C. 1990. A variant of Capgras syndrome with substitution of inanimate objects. British Journal of Psychiatry 156:883-884.

Sass, L. 1994. The Paradoxes of Delusion: Wittgenstein, Schreber, and the Schizophrenic Mind. Ithaca, NY: Cornell University Press.

Stone, T., and A. Young. 1997. Delusions and brain injury: The philosophy and psychology of belief. Mind and Language 12:327-364.

Weinstein, E. A. 1996. Reduplicative misidentification syndromes, in Method in Madness (pp. 1336), ed. P. W. Halligan and J. C. Marshall. Hove, East Sussex: Psychology Press.

Young, A. 1998. Face and Mind. Oxford: Oxford University Press.

Young, A. 1999. Delusions. The Monist 82:571-589.

Young, A. 2000. Wondrous strange: The neuropsychology of abnormal beliefs. Mind and Language 15:47-73.

Young, A., and K. M. Leafhead. 1996. Betwixt life and death: Case studies of the Cotard delusion, in Method in Madness (pp. 147-171), ed. P. W. Halligan and J. C. Marshall. Hove, East Sussex: Psychology Press.

Young, A. W., I. Reid, S. Wright, and D. J. Hellawell. 1993. Face processing impairments in the Capgras Delusion. British Journal of Psychiatry 162:695698. 